\title{
CONTRADIÇÕES E DEFICIÊNCIAS DO PROGRAMA MINHA CASA, MINHA VIDA: IMPLICAÇÕES E REBATIMENTOS SOBRE A DINÂMICA SOCIOESPACIAL DAS CIDADES MÉDIAS BRASILEIRAS
}

\author{
EDUARDO ALEXANDRE NASCIMENTO ${ }^{1}$ \\ Universidade Federal do Rio Grande do Norte
}

\section{Introdução}

Promover a universalização do acesso à moradia digna e de qualidade constitui, em tese, o objetivo central do atual programa habitacional do governo federal brasileiro. Intitulado Minha Casa, Minha Vida o referido programa tem por finalidade construir mais de três milhões de moradias no país e concretizar o "sonho da casa própria" de parte dos 5.998 milhões $^{2}$ de famílias desabrigadas ou que vivem de aluguel. De acordo com dados ${ }^{3}$ do Ministério das Cidades, entre 2009 - ano de lancamento do PMCMV - e 2014, o Programa contratou mais de 3.4 milhões de moradias em todos os estados do país e entregou 1.666.242, com investimento de $\mathrm{R} \$ 212,3$ bilhões no período.

A despeito da magnitude e abrangência numérica do PMCMV e de sua promessa de tirar milhares de famílias do aluguel, não acontece sem gerar efeitos perversos que apontam para o alcance de resultados inexpressivos, ou até mesmo para o agravamento do problema que propõe

\footnotetext{
${ }^{1}$ Doutorando do Programa de Pós-Graduação em Geografia da UFRN. Contato: eanascimentoea@gmail.com.
${ }^{2}$ Disponível em: http://www.fjp.mg.gov.br/index.php/docman/cei/deficit- habitacional/185-deficit-habitacional-2009/file . Acessado em 04/11/2014.

${ }^{3}$ Disponível em: http://www.cidades.gov.br/index.php/noticias2014.html?start=20. Acessado em: 26/09/2014.
} 
mitigar, o que o torna em certa medida contraproducente. O grande estímulo que esse programa tem dado ao mercado de imóveis é a geração de uma forte especulação imobiliária nas cidades médias e nos grandes centros urbanos do país, o que significa o encarecimento do solo urbano, dos imóveis e dos aluguéis. O principal resultado disso é que as camadas menos abastadas da sociedade terão mais dificuldades para obter moradia de qualidade. O capital, que encontra no setor imobiliário brasileiro amplamente fortalecido pelo PMCMV - condições efetivas para sua realização, reproduz-se por meio da produção do espaço urbano, “(...) criando novas contradições e aprofundando o conflito com os espaços da moradia, na medida em que os interesses do capital entram em choque com os desejos e necessidades da reprodução da vida humana" (CARLOS, 2007, p. 93).

O presente trabalho, ao buscar compreender os efeitos perversos do PMCMV sobre a realidade socioespacial das cidades médias brasileiras (considerando as repercussões desse programa sobre o espaço urbano de Mossoró/RN como referência empírica), desenvolve uma reflexão ancorada na teoria da ordenação espaço-temporal ${ }^{4}$ de Harvey (2005), a fim de demonstrar que a expansão do capital imobiliário e a implementação desse programa em Mossoró e, por conseguinte, em outros centros urbanos de porte médio do país são fenômenos diretamente vinculados à necessidade de reprodução do capital. Visam, em última análise, a solucionar as crises de sobreacumulação do sistema capitalista pelo uso e reestruturação do espaço geográfico.

Nessa perspectiva é realizado ainda um esforço de análise no sentido de examinar criticamente as principais contradições socioeconômicas presentes na cidade de Mossoró, geradas a partir do processo de reprodução de seu espaço urbano, em boa medida animado e sustentado pelo uso inadequado dos recursos oriundos da atual política de habitação do governo federal. Nessa cidade o agravamento das contradições "no e do espaço" (LEFEBVRE, 2008) como resultado direto da expansão do setor imobiliário, estimulado pelos recursos do PMCMV, mostra-se sobremodo perceptível.

${ }^{4} \mathrm{O}$ processo de ordenação espaço-temporal, segundo postula Harvey (2005), consiste numa forma particular de solucionar crises capitalistas por meio do adiamento do tempo de retorno dos ativos investidos e da incorporação ao espaço de capital fixo, na forma de infraestrutura e habitação. 


\section{Minha Casa, Minha Vida: instrumento de uma reordenação espaço-temporal capitalista}

Diante da saturação dos circuitos mais tradicionais da economia capitalista, os quais integram o domínio da produção e do consumo imediatos, o que pode ser verificado pela sobreacumulação de capitais em forma de dinheiro, de mercadoria e de mão de obra, que não encontram formas de aplicação lucrativas, é que os ativos são investidos e deslocados para circuitos outrora tidos apenas como segmentos complementares do sistema econômico prevalecente (HARVEY, 2005). O capital, sobretudo o financeiro, para se realizar hoje o faz através do espaço, isto é, produzindo e se apropriando do espaço. Isso significa dizer que o momento atual revela uma importante transformação marcada pela promoção do imobiliário e pela mobilização do solo urbano. Lefebvre postula que:

Durante muito tempo, o imobiliário, no capitalismo, só teve
uma importância menor. [...]. Outrora a construção, ramo de
produção inicialmente subordinado, quase artesanal, tinha
menos importância que a produção do aço ou do açúcar. [...].
Ora, a situação desse ramo mudou completamente, e não
apenas nos grandes países industriais. [...] o imobiliário,
doravante mobilizado (construções, especulações), torna-se
central no capitalismo [...] (2008, p. 118).

Nesse sentido, a reprodução do espaço social se desenvolve num outro patamar, revelando o espaço como dimensão significativa $\mathrm{e}$ preferencial da realização da acumulação do capital em suas mais variadas formas. A ampliação dos investimentos no setor imobiliário, que se verifica em quase todo o mundo, corrobora essa afirmação. Em entrevista recente $(2010)^{5}$, o geógrafo David Harvey afirmou que nos últimos trinta anos a maior parte dos investimentos não foi destinada à produção de bens industrializados, mas aos ativos e à valorização de ativos, como aluguéis de terras, preços de imóveis etc. Essa dinâmica de investimentos de capitais na produção e comercialização de espaços, sobretudo de espaços urbanos, que revela a crescente mercantilização da cidade, outrora circunscrita aos grandes centros metropolitanos dos países capitalistas centrais, encontra-se fortemente presente também em muitos países "terceiromundistas".

${ }^{5}$ Disponível em: http://vimeo.com/10933225 . Acessado em: 20/02/2012. 
No Brasil a presença e as ações do capital imobiliário, respaldadas pelas políticas de habitação do Estado, foram marcantes, reconfigurando profundamente os espaços urbanos do país durante as últimas três décadas, fazendo destes, importantes enclaves para acumulação capitalista. No presente período histórico a multiplicação dos empreendimentos imobiliários em território nacional ainda repercute de maneira determinante sobre a dinâmica socioespacial das cidades brasileiras, pois acarreta transformações marcantes em diversos aspectos da realidade desses municípios, bem como reestrutura e reorganiza seus territórios a fim de torná-los cada vez mais aptos à reprodução do capital.

$\mathrm{O}$ atual programa habitacional do governo federal, o PMCMV, cumpre atualmente um papel altamente importante nesse processo. Enquanto estrutura financeira para o setor de habitação, o programa figura como suporte à acumulação de riquezas, estendendo ainda mais o alcance das ações do capital imobiliário sobre os espaços urbanos do país.

A presença dos recursos financeiros desse programa, sobretudo nas cidades de grande e de médio porte do país, com ênfase nas últimas, tem tornado esses lugares bastante receptivos a esse tipo de negócios e dotados de grande potencial econômico. Dessa forma, essas cidades vêm propiciando a condução das novas estratégias de desenvolvimento do capitalismo de realizar seus lucros por meio de uma ampla reordenação espaço-temporal e de viabilizar, do mesmo modo, a ampliação dos espaços aptos ao processo de reprodução do sistema.

Os volumes de investimentos, oriundos do PMCMV, que encontram, principalmente nas grandes e médias cidades brasileiras oportunidades efetivas de realização, permitem ao capital superar parcialmente suas contradições internas. Por meio de um considerável processo de produção de moradias (em forma de condomínios e de conjuntos habitacionais) uma quantidade expressiva de capitais é incorporada ao espaço urbano, o que implica a formação de demanda para uma série incomensurável de produtos e serviços, absorvendo, a partir de várias frentes, os ativos excedentes.

Nessa perspectiva, a análise referente ao PMCMV deve, necessariamente, vinculá-lo a um amplo processo de reordenação espaçotemporal, que favorece diretamente o desenvolvimento de condições para a acumulação de capitais. 
"Com relação à sua determinação mais profunda, o sistema do capital é orientado para expansão e movido pela acumulação [...]" (MESZÁROS, 2002, p. 95), não podendo prescindir, sob pena de extinção, da continuidade sustentável dessa expansão. A competição enquanto realidade imanente da formação societal vigente, força cada capitalista a manter constantemente o aumento do seu capital. Para conservá-lo, no entanto, ele não consegue expandi-lo, exceto por meio da acumulação progressiva, o que implica a necessidade contínua de crescimento e valorização dos ativos. Entretanto, no regime capitalista a expansão da economia é um processo inerentemente antagônico que, frequentemente, irrompe em forma de crises. De acordo com Harvey (2006a, p. 78) “(...) essas crises são tipicamente registradas como excedentes de capital (...) e excedentes de força de trabalho lado a lado, sem que haja aparentemente uma maneira de conjugá-los lucrativamente (...)". Dentre os meios utilizados para atenuar a crise estrutural do capitalismo as estratégias, as reestruturações e a produção do espaço geográfico são fatores que consistem em vias autênticas de resolução das contradições internas do capital.

Os ajustes espaciais surgem como mecanismos que buscam neutralizar as tensões inerentes aos processos de acumulação do capital, criando tipos particulares de estruturas geográficas. Segundo Harvey (2005), o capital sobreacumulado, responsável pela crise, pode encontrar um campo fértil para sua absorção ao se deslocar da dimensão de consumo imediato, já saturada pela ausência de demanda efetiva, para a produção de capital fixo, como obras de infraestrutura e edificações destinadas à produção, à circulação e ao consumo, como é o caso da habitação. Assim, esses ativos são absorvidos, promovendo o restabelecimento das condições ideais para realização do lucro.

Essas asseverações, fundamentadas na teoria das "ordenações espaço-temporais" de Harvey, possibilitam pensar que a implementação do PMCMV é responsável em boa medida pelo forte incremento do processo de expansão do setor imobiliário no Brasil, provocando mudanças importantes na dinâmica geográfica, como resultado dos agentes do capital que criam e transformam o espaço na tentativa de encontrar oportunidades lucrativas para o capital sobreacumulado e, por conseguinte, de evitar a sua eventual desvalorização.

É preciso dizer que, no atual período histórico, a dinâmica expansiva do capital imobiliário e os consequentes processos de produção e reordenação do espaço urbano se reproduzem muito além dos limites 
territoriais das grandes metrópoles nacionais. As cidades médias, por exemplo, têm se mostrado lugares bastante receptivos a esse tipo de negócio. A emergência do período histórico denominado por Santos (2008) de técnico-científico-informacional, que implica a reestruturação do território e da produção, dotou e vem dotando as cidades médias de grande potencial econômico. Assim, o presente trabalho se propõe a analisar como as ações desenvolvidas pelos agentes do capital imobiliário, incentivados pelos mecanismos criados pelo PMCMV, reestruturam e reordenam o espaço urbano nessas cidades, a fim de engendrar condições de acumulação de riquezas.

A questão em foco será desenvolvida tendo a cidade de Mossoró como ponto de referência. Partindo da análise do contexto específico desse município, modificado pelas ações resultantes da implementação do PMCMV, procura-se apreender os efeitos da atual política de habitação do governo federal sobre a dinâmica socioespacial das cidades médias brasileiras. Mossoró, como estudo de caso, não consiste no escopo fundamental do texto. A preocupação central aqui é desenvolver uma reflexão crítica de caráter geral sobre como as determinações mercadológicas do programa habitacional em questão engendram um processo de reprodução do espaço urbano, sobretudo nas cidades médias, extremamente contraditório e com grandes custos sociais. "A premissa é que o estudo de um fenômeno específico produz, em diferentes escalas, as mesmas determinações da totalidade, sem com isso eliminarem-se as particularidades históricas" (CARLOS, 1994, p. 39). Assim, este trabalho postula que o presente processo de reprodução do espaço urbano mossoroense, com todos os seus desdobramentos, instaurado e sustentado em boa medida pela aplicação dos recursos do PMCMV, se reproduz, obviamente que resguardando suas inúmeras peculiaridades, em várias porções do território nacional, replicando sua lógica segregadora.

\subsection{As implicações do programa Minha Casa Minha Vida sobre o processo de reorganização espacial nas cidades médias brasileiras}

$\mathrm{O}$ advento das cidades médias brasileiras, enquanto elemento imprescindível para o crescimento da economia e da reorganização do território nacional consiste em um fator determinante na apreensão do atual processo de expansão do volume de empreendimentos imobiliários realizados no território nacional. A recente dinâmica expansiva do capital 
imobiliário, fortemente embalada pelos recursos provenientes do PMCMV, reproduz-se não apenas como nos tempos de outrora, nos marcos territoriais dos grandes centros urbanos brasileiros, mas também nos centros menores e médios, fazendo-se fortemente presente sobretudo nas cidades médias, representando para esses espaços urbanos alterações profundas em sua realidade.

Nesse sentido as cidades médias figuram, no presente momento, como espaços que reúnem condições ideais para a realização desses tipos de negócios. A emergência do período histórico denominado por Santos (1997) de técnico-científico-informacional, que implica a reestruturação do território e da produção, dotou e vem dotando as cidades médias de grande potencial econômico. Esse tipo de cidade atualmente abriga instituições de ensino superior e/ou profissionalizantes que promovem o amplo treinamento da mão de obra local, redes de fibra óptica para a transmissão de fluxos de informações e sistemas de circulação de mercadorias, bem como sistemas de engenharia modernos de provimento de energia elétrica, etc. Esse novo conjunto de forças produtivas é responsável por um profundo processo de reestruturação econômica e territorial no Brasil, desenvolvendo principalmente no âmbito das cidades médias condições que permitem os atores do capital realizar investimentos com baixos custos de produção. Parafraseando Contel (2010), pode-se afirmar com isso que uma característica marcante do crescimento das cidades médias atualmente é que elas reproduzem parte das lógicas que eram, até recentemente, eminentemente metropolitanas, entretanto. Um exemplo disso são os empreendedores imobiliários e a especulação imobiliária como negócio, que agora se integra à lógica reprodutiva das cidades médias.

Dessa maneira as cidades médias, em face da pujança econômica que apresentam, compõem enclaves geográficos propícios à ampliação das ações do capital imobiliário. $\mathrm{O}$ capitalismo encontra nesses centros as condições ideais para realizar seu processo irrestringível de acumulação. No caso específico do setor imobiliário o acréscimo constante e maciço de capital fixo ao território permite ao sistema vigente de produção de mercadorias produzir e reproduzir o espaço, ampliando suas forças e corrigindo, assim, temporariamente, suas contradições internas pois, como diz Harvey (2006b), o capitalismo tem recorrido repetidas vezes à reorganização geográfica como solução parcial para suas crises e seus impasses. 
A multiplicação de empreendimentos imobiliários nas cidades médias brasileiras, que beneficia largamente a classe empresarial forjando condições para a realização de investimentos e fazendo avançar o processo de acumulação capitalista, vincula-se necessariamente à profusão do crédito, pressuposto fundamental para o financiamento de imóveis e a implementação de programas habitacionais. Portanto, a compreensão da dinâmica do fenômeno imobiliário que marca de forma indelével o atual quadro socioeconômico dos municípios de porte médio do país, deve necessariamente considerar o papel do Estado com suas políticas de habitação, enquanto importante agente fomentador desse processo. Os volumosos recursos financeiros liberados pela atual política habitacional do governo federal (Minha Casa, Minha Vida) encontram-se na base de um expressivo reordenamento espaço-temporal que se verifica no redimensionamento e no fortalecimento do mercado imobiliário em boa parte do território nacional.

Os capitais provenientes desse programa, que se estendem às cidades médias, se fazem presentes repercutindo de forma decisiva sobre seus processos socioeconômicos e sobre suas estruturas territoriais. Na medida em que o uso desses recursos estimula a produção de imóveis, incorporando uma grande massa de capital ao território, a economia tende a se dinamizar. Construções de conjuntos habitacionais e condomínios, além de gerar um incremento nas atividades dos ramos diretamente evolvidos com a produção imobiliária (construtoras, incorporadoras, imobiliárias, indústrias envolvidas com a produção de materiais de construção, etc.), geram uma significativa demanda por produtos em outros ramos da economia - dentre os quais é possível destacar: os setores de publicidade e marketing, os centros e as escolas para formação de mão de obra especializada, como técnicos em construção civil e corretores de imóveis etc. -, o que terá importantes implicações também sobre o mercado de trabalho, com aumento do número de empregos. A ação do capital vinculado ao PMCMV que circula no setor imobiliário tem promovido, da mesma forma, o acréscimo substancial de objetos ao espaço urbano das cidades médias. A construção de edifícios verticalizados comerciais e residenciais, assim como de condomínios horizontais fechados e de conjuntos habitacionais, vem alterando profundamente a paisagem da cidade. Essas transformações, que ocorrem em ritmo bastante acelerado e de maneira acentuada, redimensionam a forma, a aparência e faz surgir novos conteúdos no espaço urbano. Este novo conjunto relacional de "forma-conteúdo" engendra uma nova dinâmica geográfica da qual resulta 
um novo modo de viver e conviver, uma nova forma de morar, novas práticas de lazer, etc. Os desdobramentos dessa nova realidade espacial atingem ainda a dimensão subjetiva do ser social, despertam nele novos desejos e novos projetos de vida.

A exemplo dessa realidade, as transformações que atualmente ocorrem em Mossoró, reconfigurando simultaneamente os contornos de sua realidade econômica e de sua dinâmica socioespacial, forjam um cenário que ilustra com certa precisão o impacto do PMCMV sobre as cidades médias brasileiras. Nessa perspectiva, a observação associada a uma reflexão crítica dos processos ligados à ampliação e ao fortalecimento do mercado imobiliário desse município, que se desdobram em seu interior acarretando uma série de mudanças, propicia o desenvolvimento de uma análise alimentada com dados materiais comprobatórios, a qual visa a sustentar empiricamente as proposições referentes às cidades médias contidas neste artigo.

Mossoró, importante centro regional nordestino, nos últimos tempos integra-se mais intensamente à lógica da acumulação capitalista. Os processos de modernização e reestruturação econômica e territorial do Nordeste brasileiro, que se desdobram efetivamente a partir do início dos anos 1990 promovidos pela globalização e pelo advento do período técnico-científico, inserem a cidade de forma mais profunda nos circuitos de reprodução do capital (ELIAS, 2006). Neste novo momento, marcado pelo fortalecimento das relações capitalistas na região Nordeste, a ação das forças do capital em território mossoroense tem engendrado a reunião de um conjunto de condições favoráveis ao expressivo incremento do setor imobiliário na cidade. Isso se evidencia pela quantidade de investimentos aplicados no desenvolvimento de obras de infraestrutura e na construção de condomínios residenciais, destinados às classes média e alta, e de conjuntos habitacionais populares.

Nos últimos dez anos o setor imobiliário em Mossoró cresceu muito além da média nacional, fenômeno que ganha ainda mais intensidade com a emergência do PMCMV. Levando em consideração as devidas proporções, os dados divulgados na imprensa local em 2011 pelo Sindicato da Indústria da Construção Civil do Rio Grande do Norte, seção Mossoró (SINDUSCON), apontam para um crescimento superior a $400 \%$ nesse período, enquanto em âmbito nacional, a média de crescimento do setor não superou os 45\% no mesmo espaço de tempo (Tribuna do Norte, 2011). Segundo o presidente do SINDUSCON-RN, seção Mossoró, no período 
compreendido entre 2008 e 2011 a indústria da construção civil investiu na cidade em torno de 30 a 40 milhões de reais ao mês, que vão desde a construção de unidades de pequeno porte destinadas a uma classe média que vem se fortalecendo e se ampliando nos últimos anos, até a construção de apartamentos de luxo com valores superando os $\mathrm{R} \$ 900.000,00$ (novecentos mil reais) localizados em bairros nobres da cidade, por exemplo Nova Betânia e Ulrik Graff ${ }^{6}$.

Esse fenômeno tem sido um dos vetores decisivos para o forte crescimento da economia local, bem como para o atual processo de reprodução e modernização do espaço urbano do município, visto que uma grande parcela do conjunto desses investimentos se incorpora ao território causando mudanças profundas em sua materialidade e em sua dinâmica, e provocando alterações determinantes no conjunto das relações sociais da cidade. A exemplo de outras cidades de porte médio no país a dinâmica do setor imobiliário em Mossoró, que resulta em um novo sistema de formas geográficas e na emergência de novas relações espaciais, pode ser demonstrada teoricamente a partir de determinações de um contexto geral marcado por arranjos espaço-temporais que possibilitam a criação de oportunidades importantes para investimentos lucrativos tanto para capitais locais quanto para capitais externos.

Os mecanismos de crédito, bem como as políticas de regulamentação criadas e sustentadas pelo PMCMV, viabilizam em boa medida o presente processo de expansão do capital imobiliário em Mossoró, tendo importantes impactos sobre a estrutura socioeconômica e sobre o processo de modernização do espaço urbano desse município.

A multiplicação dos investimentos do setor imobiliário, ultimamente ampliado pelos recursos do PMCMV, tem impactado vários segmentos da economia local, como resultado direto da ampliação do consumo produtivo. Dentre os ramos da economia diretamente envolvidos no mercado imobiliário é possível perceber a multiplicação na cidade do número de incorporadoras, de construtoras, de imobiliárias e de lojas especializadas na venda de materiais para construção. A publicidade, o marketing, as universidades e os centros de capacitação profissional são setores que integram a estrutura econômica do lugar, que, mesmo não tendo relação direta com as atividades do mercado imobiliário, vivenciam

${ }^{6}$ Dados obtidos em pesquisa de campo realizada em maio de 2012. 
um significativo incremento, o que denota a relação entre dinâmica do imobiliário e o desenvolvimento de condições para a realização de investimentos lucrativos.

No tocante ao mercado de trabalho, o Cadastro Geral dos Empregados e Desempregados - órgão vinculado ao Ministério do Trabalho - revelou que nos últimos cinco anos Mossoró tem registrado um crescimento substancial no número de empregos no mercado imobiliário. Só em 2010, segundo dados do órgão, foram cerca de dois mil e quinhentos empregos gerados diretamente ${ }^{7}$. Ainda, em entrevista recente a um jornal local (Jornal de Fato), o presidente do SINDUSCON-RN, seção Mossoró, tratando do crescimento da verticalização da cidade acima da média nacional, afirmou que o setor emprega direta e indiretamente mais de doze mil trabalhadores. Os números apresentados aqui referentes aos postos de emprego gerados em virtude do crescimento dos negócios no setor imobiliário demonstram o grau de repercussão da expansão deste setor sobre a dinâmica da economia local.

É necessária, além disso, a realização de um esforço de análise no sentido de trabalhar a dimensão das transformações decorrentes da ampliação das atividades do capital imobiliário sobre a estrutura geográfica de objetos e de relações que integram o espaço urbano mossoroense. Haja vista o grande número de construções (sobretudo construções verticalizadas) representar o delineamento de um importante processo de reorganização do território do município. Informações do setor de protocolo e emissão de alvarás da Secretaria Municipal de Desenvolvimento Territorial e Meio Ambiente (SEDETEMA) revelam que entre o ano de 2008 e o primeiro mês do ano de 2013, Mossoró possuía aproximadamente 4.500 unidades habitacionais em construção, entre casas e apartamentos. Esses dados indicam que nos últimos cinco anos (período que coincide com o lançamento do PMCMV) houve um importante incremento no número de construções, se comparado a anos anteriores. Entre 2003 e 2007, por exemplo, foram emitidos alvarás para construção de 1.445 unidades habitacionais, menos da metade de autorizações do período de 2008 a 2013. Essa profusão de construções em Mossoró representa a incorporação de uma quantidade expressiva de novas formas

\footnotetext{
${ }^{7}$ Disponível em: http://portal.mte.gov.br/delegacias/pr/cadastro-geral-de-empregados-edesempregados-caged/ Acessado em: 01/03/2012.
} 
geográficas ao espaço urbano do município, o que altera profundamente sua configuração espacial.

A presença dos recursos do PMCMV em Mossoró representa uma série de importantes mudanças, como o incremento da economia - com a ampliação do consumo e a geração de empregos - e a modernização do espaço - com a construção de vários condomínios, tanto verticais quanto horizontais -, o que modifica a morfologia urbana do município dando a ele uma "atmosfera de progresso". Não obstante essas mudanças acarretam uma série de contradições socioespaciais e econômicas que atingem, sobretudo, os indivíduos mais pobres. Tal fato se explica devido ao uso dos recursos do programa em questão estar subordinado às necessidades de reprodução geral das relações sociais e espaciais de produção e, por conseguinte, ao ímpeto implacável de acumulação do capital.

$\mathrm{O}$ atual programa habitacional do governo federal que, em tese, busca superar pelo menos em parte o grave problema de moradia enfrentado pelas classes sociais menos abastadas, surge como um importante entrave ao acesso dessas classes à moradia de qualidade. Aparentemente os imóveis financiados pelo PMCMV apresentam preços que estão muito além da realidade financeira da população sem teto. A partir de uma busca realizada em um endereço eletrônico ${ }^{8}$ que reúne grande parte das imobiliárias e construtoras em atividade na cidade de Mossoró, constatou-se que os preços das unidades habitacionais financiáveis pelo programa apresentam valores sempre superiores a $\mathrm{R} \$$ 95.000.00 (noventa e cinco mil reais), o que inviabiliza a aquisição dessas unidades para a maior parte da população. Assim, é pertinente presumir que as políticas públicas desenvolvidas no sentido de atenuar o problema habitacional no Brasil têm se mostrado ineficientes, já que a forma como os recursos são aplicados a partir desses programas tem fomentado uma forte especulação no mercado imobiliário e, consequentemente, o encarecimento dos imóveis.

\footnotetext{
${ }^{8}$ Disponível em: http://www.mossoroimoveis.com.br/index.php Acessado em: $05 / 11 / 2014$.
} 


\subsection{O papel do Estado na implementação do processo de reordenação espaço-temporal}

As ações do sistema do capital no sentido de produzir e reestruturar o espaço geográfico, a fim de viabilizar sua reprodução, não acontece sem o auxílio do Estado. O fluxo de capitais para o circuito imobiliário estipula necessariamente o empenho de um Estado intervencionista capaz de criar uma estrutura financeira e engendrar arranjos institucionais indispensáveis à realização dos investimentos no setor. Estabelece-se uma parceria no modo capitalista de produção em que o Estado desempenha alguns papéis extremamente relevantes. Primeiro como propiciador de um ordenamento, por meio de normas e leis, regulando o uso do espaço a partir das determinações do mercado; segundo no estabelecimento de recursos financeiros e na execução de projetos imobiliários, tais como a implantação de equipamentos de infraestrutura e a criação de um fundo de consumo em forma de edifícios residenciais e comerciais. $\mathrm{Na}$ atual fase do capitalismo, na qual a maior parte dos investimentos se concentra nos ativos ligados aos mercados financeiro e imobiliário, o Estado cria mecanismos que permitem que recursos sobreacumulados de investidores locais e nacionais, envolvidos com outros segmentos da economia, sejam deslocados para o setor imobiliário, para a produção de infraestruturas físicas e sociais, dinamizando a economia a partir de ordenações espaço-temporais. Nesse caso, o Estado proporciona amplas condições à acumulação do capital por meio da reprodução e reestruturação do espaço geográfico.

O Estado, no processo de produção do espaço sob as determinações da ordem socioeconômica vigente, através de suas políticas, cumpre seu papel de "comitê executivo do capital", atendendo basicamente aos interesses e aos reclamos da acumulação de riquezas. Nesse mesmo diapasão, mediante a necessidade de encontrar escoadouros para investimentos econômicos e arrefecer parcialmente as crises de sobreacumulação, o poder público no Brasil, em associação com o capital privado, vem atuando por meio do planejamento estratégico no sentido de promover os ajustes espaciais necessários à realização do lucro.

O papel que o Estado capitalista desenvolve na produção do espaço geográfico brasileiro contribui de forma determinante para pensar o novo programa nacional de habitação (Minha Casa, Minha Vida) enquanto estratégia fomentada no sentido de favorecer o aspecto econômico, pois a partir dos milhares de empreendimentos imobiliários, subsidiados por esse 
programa, que reconfiguram o espaço urbano nacional, uma parcela considerável de capitais encontra condições efetivas de reprodução. Esse fato contrasta radicalmente com a proposta original do programa, que consistia em superar contradições sociais ligadas à concentração do solo urbano e de imóveis nas cidades brasileiras. A forma como os recursos do programa vem sendo utilizados, sendo geridos segundo as regras do mercado, agrava as antigas contradições socioespaciais e faz surgir novas contradições, complicando ainda mais a situação de milhões de famílias que habitam as áreas urbanas do Brasil. No entanto, esse é um processo que se reveste de aparência e mascara-se com ideologias. $O$ discurso mistificador produzido pelos ideólogos da ordem hegemônica desorienta os indivíduos, ocultando-lhes o verdadeiro sentido dos fatos.

Os reais objetivos envolvidos no desenvolvimento das políticas de habitação do governo federal são encobertos, em primeiro lugar, por um arcabouço legal que postula o Estado com "ente neutro e independente", acima dos interesses de classes, a fim de solucionar conflitos e discrepâncias sociais, sempre visando ao bem comum. Em segundo lugar, existe atualmente, com esse mesmo fim, uma sofisticada campanha publicitária, veiculada nos mais diversos meios de comunicação, no sentido de convencer a sociedade dos fins sociais do programa. Quando tudo permite pensar que se tronou possível o sonho da casa própria, “[...] o que é imposto aos espíritos é um mundo de fabulações, [...] que se aproveita do alargamento de todos os contextos para consagrar [...]" (SANTOS, 2007, p. 18), pelo ordenamento socioespacial, calcado na expansão do capital imobiliário, o metabolismo de reprodução social prevalecente.

\section{Minha Casa, Minha Vida: efeitos perversos, alienação e fragmentação socioespacial}

Os agentes do capital em associação direta com as instituições públicas, visando a conservar intactas as estruturas fundamentais da ordem socioeconômica prevalecente, criam estratégias para manter o fluxo de acumulação do capital. O espaço, sobretudo hoje, torna-se lugar e meio no qual se desenvolvem tais estratégias, tornando-se interessante instrumento de acumulação para o capital. É imperativo o uso do espaço como instrumento de reprodução do capital. Lefebvre, ao afirmar que o 
capitalismo se manteve (e se mantém) pela conquista e integração do espaço, postula a ideia de mobilização do imobiliário e diz que:

O mercado da habitação se generaliza (...). A construção deixa de ser um ramo industrial secundário, um setor subordinado da economia. Ela torna-se um setor primordial. Ela não desempenha apenas o papel de feedback, de equilíbrio, de retomada, mas um papel estimulante na economia atual; tornando-se um ramo essencial da produção (1972, p. 152).

Dessa forma, pode-se afirmar que a reprodução do espaço urbano mossoroense a partir da dinâmica do imobiliário consiste num ajuste espacial visando unicamente à reprodução do capital. $\mathrm{O}$ espaço integrado e produzido tendo em vista esse fim é mobilizado pela valorização capitalista, seu acesso doravante se dá por meio das relações de troca. Disso resulta o agravamento do problema da justiça social na cidade, em que o "(...) capital constrói, destrói e reconstrói o espaço à sua semelhança de maneira que quem tem, tem, e quem não tem, fica sem (...)" (Valença, 2008, p. 248). A partir da intensificação da dinâmica do imobiliário que ocorre dentro dos marcos da economia de mercado, o espaço urbano mossoroense se reproduz no interior dessa lógica gerando um forte processo de segregação espacial e exclusão social, imprescindível à acumulação do capital.

À medida que qualquer subespaço se abre positivamente à ação do capital imobiliário, processa uma tendência de crescente valorização dos imóveis e da terra, dificultando, e até mesmo impossibilitando, as classes menos favorecidas em ter acesso a bens imobiliários no meio urbano; acentuando-se, dessa forma, a concentração de riquezas, o que agrava as discrepâncias socioeconômicas. O espaço produzido sob as determinações da ordem do capital firma-se na "(...) apropriação privada, que aliena o produtor do produto; nesse sentido, o espaço se produz a partir da contradição entre sua produção socializada e apropriação individual" (CARLOS, 1994, p. 22), impedindo o acesso generalizado das classes sociais à terra e aos equipamentos geográficos construídos.

Essa lógica, marcada pela mobilização da venalidade generalizada do espaço, instala-se em Mossoró com vigor fazendo do espaço urbano nessa cidade uma "nova raridade". Raridade? E o que dizer dos espaços livres e sem uso, que são abundantes no município? Sumiram? Não, foram 
integrados às tramas do capital, sua posse, tornando-se agora restrita a uma parcela privilegiada da sociedade. "A carestia do espaço assim ocupado e rarefeito é um fenômeno, com consequências cada vez mais graves" (LEFEBVRE, 2008, p. 54).

Considerando tal proposição, torna-se possível afirmar que o atual programa habitacional do governo federal - o qual, em tese, busca resolver o grave problema de moradia enfrentado pelas classes sociais com menor poder aquisitivo nas cidades brasileiras e, no caso específico, em Mossoró - surge como grande obstáculo ao acesso dessas classes à moradia digna. Aparentemente, os imóveis financiados em Mossoró e em outras cidades médias do país por esse programa apresentam preços altos, que estão muito além da realidade financeira da população sem teto. Assim, é pertinente presumir que as políticas públicas desenvolvidas no sentido de atenuar o problema habitacional no Brasil têm se mostrado ineficientes, já que a forma como os recursos são aplicados a partir desses programas tem fomentado uma forte especulação no mercado imobiliário e, por conseguinte, o encarecimento dos imóveis. É certo que isso acontece porque, do ponto de vista do capital, o que importa, naturalmente, não é a avaliação das implicações humanas de um processo econômico objetivo, mas a criação de condições necessárias ao funcionamento e à reprodução sem perturbações do modelo produtivo vigente.

A pressão do mercado imobiliário que encarece, sobremaneira, os imóveis e o solo urbano - o metro quadrado, segundo o SINDUSCON-RN, seção Mossoró, custa em torno de $\mathrm{R} \$ 2.000 .00$ (dois mil reais) nos bairros menos valorizados da cidade ${ }^{9}$ - provoca a segregação espacial, empurra um número significativo de famílias para as periferias mal servidas de equipamentos urbanos e de serviços básicos, comprometendo a qualidade de vida de milhares de pessoas. Assim, notadamente, há um contraste marcante entre a realidade concreta e os termos formais que estão postos no texto do novo programa nacional de habitação, o qual promete "(...) assegurar à população acesso à moradia digna, à terra urbanizada, à água potável, ao ambiente saudável e à mobilidade com segurança" (2004, p. 3) ${ }^{10}$.

${ }^{9}$ Disponível em: http://geaconsultoria.blogspot.com/2011/03/mossoro-rn.html . Acessado em: 28/03/2012.

${ }^{10}$ Disponível em: http://www.cidades.gov.br/ . Acessado em: 03/04/2012. 
Da mesma forma, esse violento processo de especulação imobiliária que viceja em Mossoró acentuando seus problemas sociais promove de maneira exponencial a elevação dos aluguéis, tendo fortes implicações sobre a renda de muitas famílias, sobretudo daquelas de menor poder aquisitivo, na medida em que elas passam a comprometer uma parcela cada vez maior de seus rendimentos, já insuficientes para suprir suas necessidades, com o pagamento da locação de residências. A elevação dos preços dos aluguéis, que acontece a passos cada vez mais largos, além de comprometer a renda familiar da população mais pobre precarizando sua condição material, coloca muitos chefes de família numa condição de grande incerteza quanto a sua necessidade de mordia. O que se explica também pela consideração do intenso processo de precarização do trabalho conduzido pelas políticas neoliberais.

A emergência do padrão neoliberal de produção flexível, que substitui o regime fordista-keynesiano, representa mudanças radicais no universo do trabalho no contexto do capitalismo contemporâneo. Há, em função disso, uma tendência extremamente significativa de "subproletarização do trabalho, presente nas formas de trabalho precário, parcial, temporário, subcontratado, 'terceirizado', vinculados à economia informal, entre tantas modalidades existentes" (ANTUNES, 2010, p. 49, grifo do autor). Essas diversas categorias de trabalhadores compartilham a precariedade do emprego e da remuneração. Desse modo, o emprego cada vez mais mal remunerado, fugaz e instável submete o trabalhador sem teto ao drama do despejo iminente de sua moradia, já que ele atua em um emprego que só pode garantir hoje, dada a instabilidade existente no mercado de trabalho.

No presente momento histórico, quando o sistema do capital exibe claros sinais de esgotamento, a humanidade vivencia uma condição de alienabilidade total, que se estende a todos os aspectos, aprofundando a fragmentação da vida humana, dada tanto no plano do indivíduo quanto no plano do espaço. Nesse contexto, as cidades vivem à sombra da "vendabilidade universal", em que "(...) predomina a tendência em converter tudo em objeto vendável" (MESZAROS, 2006, p. 36), na qual tempo, espaço, seres humanos, cultura, etc. figuram meramente como mercadoria; todos se encontram submissos ao consumo e à troca. Nesses espaços, os valores de troca finalmente se impuseram em toda sua plenitude aos valores de uso. 
Como consequência da condição de alienabilidade total dos indivíduos, marca do nosso tempo, tem-se a exclusão de determinados grupos e classes sociais do espaço urbano. As obras criadas no espaço urbano pelos e para os homens, a partir das quais estes se reproduzem realizando sua humanidade, são subordinadas aos interesses de grupos hegemônicos, que, através delas, realizam seus propósitos: “(...) organizar os fluxos diversos subordinando-os às regras institucionais; subordinar, por conseguinte, o espaço ao poder; controlar o espaço e reger, tecnocraticamente, a sociedade inteira, conservando as relações de produção capitalistas" (LEFEBVRE, 2008, p. 73) e, ainda, exercer controle sobre a classe trabalhadora, pois, como postula Harvey (2006), a dimensão espacial consiste num instrumento relevante no controle da classe trabalhadora.

Os processos de exclusão e segregação no espaço urbano se dão, ainda, em função da entrada cada vez mais acirrada do solo urbano nos circuitos de acumulação do capital (fato, até recentemente, mais comum nas metrópoles). Em Mossoró esse elemento resulta na fragmentação do espaço urbano no que concerne ao seu uso. Do mesmo modo, essa fragmentação surge como justaposição de atividades parcelares cujo conjunto escapa ao indivíduo. Esse fenômeno, inerente ao espaço urbano contemporâneo no que diz respeito a sua forma de ocupação, é resultante de sua comercialização realizada no interior dos marcos do mercado. Nesse caso, o espaço é fracionado para ser vendido em fragmentos, o que permite o domínio de porções cada vez mais consideráveis do espaço urbano pelas classes economicamente dominantes na medida em que a aquisição da terra se dá quase que unicamente pelo mercado, o que dificulta e limita significativamente o uso e a ocupação do espaço urbano pela maior parte da população. "Como consequência temos um processo de produção espacial onde a reprodução da vida nem sempre apresenta as condições mínimas de subsistência” (CARLOS, 1994, p. 195).

\section{Considerações finais}

A nova etapa de desenvolvimento do sistema do capital, caracterizada pela exaustão de modelo produtivo vigente, representa um conjunto de mudanças nas formas de produção do espaço geográfico sobretudo nas cidades médias contemporâneas, redimensionando a forma da sociedade se relacionar com a estrutura espacial. Em face disso, capital 
e Estado estão ativamente engajados no processo de dominar e produzir espaço, visando a contornar as crises desse modelo de reprodução social, que são cada vez mais agudas e persistentes. O custo social desse processo é alto, uma vez que concentra ainda mais a terra, negando à maior parte dos indivíduos o direito ao espaço e, por conseguinte, a uma série de recursos necessários à realização da vida. $\mathrm{O}$ espaço humano, como diz Lefebvre (2008), torna-se uma raridade, sendo usufruído em sua plenitude apenas por um número restrito de privilegiados, que se apropria pela violência do dinheiro daquilo que deveria pertencer ao gênero humano.

Partindo dessa perspectiva este artigo procurou desenvolver uma reflexão (tomando Mossoró/RN como marco empírico) sobre como essa forma de reprodução do espaço urbano, desenvolvida a fim de viabilizar a acumulação de capitais, acontece nas cidades médias brasileiras. A ênfase recai principalmente sobre os impactos desse processo, que incidem sobre o quadro social dessas cidades a partir do forte avanço do setor imobiliário estimulado e mantido pelas políticas públicas de habitação do governo federal. No entanto, é preciso dizer que as observações contidas neste texto referentes às implicações do atual programa de habitação Minha Casa, Minha Vida sobre a dinâmica da reprodução do espaço urbano nos centros médios do país propõem discutir apenas algumas facetas das variadas e complexas questões envoltas nesse processo. Os efeitos perversos resultantes da expansão do capital imobiliário - amplamente estimulados pelos recursos desse programa - que fragmentam o espaço e a vida de boa parte da população desses municípios são abordados aqui de forma ainda muito incipiente, não podendo apreender a dinâmica do processo de forma satisfatória.

A intenção não é a de determinar definitivamente os contornos e a natureza desse fenômeno. Postula-se aqui uma pesquisa propriamente dita, resultante do esforço sistemático de levantamento de dados empíricos. A intenção primária consiste em simplesmente refletir e suscitar algumas questões, bem como identificar algumas tendências a partir de um olhar. A observação, ainda que não permita ao indivíduo chegar à essência de um fato, contribui, desde que vinculada à reflexão, decisivamente para o movimento que se dá do desconhecido em direção ao conhecimento.

Diante da análise lançada sobre o que preconiza o atual programa de habitação do governo federal e o olhar sobre as ações empreendidas por este nas cidades médias do país, tendo a cidade Mossoró como exemplo, podemos inferir que o mesmo, na prática, não atende ao seu objetivo 
principal: promover a universalização do acesso à moradia digna e de qualidade às famílias desabrigadas ou que vivem de aluguel, ou seja, a população carente, que não tem condições de adquirir casa própria. De fato, quando analisamos a realidade dos empreendimentos construídos e em construção na cidade de Mossoró percebemos que eles apresentam custos elevados e que a população de baixa renda e carente de moradia não tem condições de adquiri-los. Com efeito, tais empreendimentos estão sendo construídos para atender a uma demanda de poder aquisitivo mais elevado e que, muitas vezes, adquirem tais imóveis com o propósito de auferir renda. Portanto, mais uma vez, a política habitacional do país não resolverá o problema de moradia, haja vista o modelo que vem se configurando a partir de sua implantação. Ou seja, está voltada para um segmento social mais bem remunerado em detrimento do segmento de menor renda e que realmente não detém o direito de moradia. Essa contradição é resultado da relação do programa com a lógica do mercado, qual seja, construir moradia para uma população que possa pagar pelos custos da obra e pelos altos lucros que o capital imobiliário possa alcançar.

\section{CONTRADIÇÕES E DEFICIÊNCIAS DO PROGRAMA MINHA CASA, MINHA VIDA: IMPLICAÇÕES E REBATIMENTOS SOBRE A DINÂMICA SOCIOESPACIAL DAS CIDADES MÉDIAS BRASILEIRAS}

Resumo: Fortemente sustentado a partir dos recursos liberados pelo mais recente programa habitacional do governo federal, o Minha Casa, Minha Vida (PMCMV), a expansão do setor imobiliário no Brasil promove o agravamento de inúmeros problemas sociais que adquirem, com isso, contornos ainda mais contraditórios, na medida em que os recursos oriundos desse programa, pelo menos em tese, visam à superação parcial de certas injustiças que caracterizam o quadro social brasileiro. Assim, o objetivo central deste trabalho consiste em tentar compreender o aprofundamento das contradições socioespaciais que caracterizam a realidade das cidades médias brasileiras, através do estudo de caso no município de Mossoró/RN, como fenômeno decorrente da expansão do capital imobiliário - subsidiado, em larga medida, pelas políticas de habitação do governo federal. Esta análise também nos conduz à reflexão sobre as reais finalidades contidas no referido programa, pois, a despeito do seu caráter social e da natureza pública de seus recursos, aparentemente 
seu escopo central é viabilizar a acumulação capitalista, favorecendo amplamente os agentes imobiliários.

Palavras-chave: Programa habitacional. Dinâmica socioespacial. Cidades médias. Desigualdades socioespaciais.

CONTRADICTIONS AND DEFICIENCIES OF MINHA CASA, MINHA VIDA GOVERNMENT HOUSING PROGRAM: IMPLICATIONS AND REVERBERATIONS ON THE SOCIO-SPATIAL DYNAMICS OF MEDIUM-SIZED BRAZILIAN CITIES

Abstract: The latest federal housing program is strongly supported from resources released by the program called Minha Casa, Minha Vida (PMCMV). The expansion of real estate in Brazil promoted the worsening of many social problems that acquire further contradictory outlines, as resources arising from this program, at least in theory, aimed at partial overcoming of certain injustices that characterize the Brazilian social context. The aim of this paper (having Mossoró-RN city as case study) is trying to understand the level of contradictions that characterize the sociospatial reality of Brazilian medium-sized cities, as a phenomenon resulting from the expansion of real estate capital, largely subsidized by housing policies of federal government. This analysis has also led us to reflect on the real objectives contained in that program; despite social and public nature of its resources, apparently its central scope is to enable central capitalist accumulation, favoring widely the estate agents.

Keywords: Housing program. Socio-spatial dynamics. Medium-sized cities. Socio-spatial inequalities.

\section{Bibliografia}

ANTUNES, Ricardo. (2010) Adeus ao trabalho? 14. ed. São Paulo: Cortez.

CARLOS, Ana Fani Alessandri. (1994) A (re)produção do espaço urbano. São Paulo: EDUSP.

. (2007) O espaço urbano: os novos escritos sobre a cidade. São Paulo: Labur Edições. 
CONTEL, Fábio Betioli. (2010) Rede urbana e cidades médias no Brasil: abordagens clássicas, abordagens contemporâneas. In. HOLANDA, V.C.C. de; AMORA, Zenilde Baima (orgs.). Leituras e saberes sobre o urbano. Fortaleza: Expressão.

ELIAS, Denise. (2006) Agronegócio e desigualdades socioespaciais. In. ELIAS, Denise; PEQUENO, Renato (orgs.). Difusão do agronegócio e as novas dinâmicas socioespaciais. Fortaleza: Banco do Nordeste do Brasil.

HARVEY, David. (2005) O novo imperialismo. 2. ed. São Paulo: Edições Loyola.

Annablume.

. (2006a) A produção capitalista do espaço. 2. ed. São Paulo:

. (2006b) Espaços de esperança. 2. ed. São Paulo: Edições Loyola.

HUGHES, P. Javier Aguerre. (2004) Segregação socioespacial e violência na cidade de São Paulo: referências para a formulação de políticas públicas. Perspec, São Paulo, v. 18, n. 4, out./dez.

LEFEBVRE, Henri. (2008) Espaço e política. Belo Horizonte: UFMG.

MÉSZÁROS, István. (2002) Para além do capital: rumo a uma teoria da transição. São Paulo: Boitempo.

. (2006) A teoria da alienação em Marx. São Paulo: Boitempo.

SANTOS, Milton. (1997) A natureza do espaço: técnica e tempo, razão e emoção. 2. ed. São Paulo: Hucitec.

. (2007) Por uma outra globalização. 14. ed. Rio de Janeiro:

$\overline{\text { Record. }}$

$\overline{\text { EDUSP. }}$.

(2008) Metamorfoses do espaço habitado. 6. ed. São Paulo:

VALENÇA, Márcio Morais. (2008) Ensaio sobre a dinâmica do imobiliário em Harvey. In. Mauad X.

FREIRE, P. Sérgio. (2011) Verticalização cresce acima da média. Tribuna do Norte, Natal, 24 jun. 2011. Disponível em: http://tribunadonorte.com.br/noticia/verticalizacao-cresce-acima-damedia/189930 . Acessado em: 30 maio 2012.

Data de submissão: 17/07/2012.

Data de aprovação: 12/11/2014. 